Original Research Article

\title{
Observation on hypothermia among infants less than 2 months in urban slums of Indore City
}

\author{
Singh $D^{1}$, Singh M.P ${ }^{2}$ \\ ${ }^{1}$ Dr. Deepti Singh, Assistant Professor, Department of Paediatrics R.K.D.F. Medical College Hospital and Research \\ Centre, Bhopal (MP), India, ${ }^{2}$ Dr. Mahendra Pratap Singh, Assistant Professor, Department of Physiology Amaltas \\ Institute of Medical Sciences, Dewas (MP), India.
}

Address for Correspondence: Dr. Deepti Singh, Assistant Professor, Department of Paediatrics, Address: OLIVE, 277, Ruchi Lifescapes, Jatkhedi, Hosangabad Road, Bhopal (M.P.). Email: dr.singhdeepti93@ gmail.com

\begin{abstract}
Aim: To study Hypothermia in infants of less than 2 months of age in urban slums of Indore city. Methods: Retrospective, cross-sectional observational study of 411 infants of below 2 months of age. Period of study: 1 year (August 2015 to August 2016) Results: Infants below 2 months of age when studied in home deliveries; conducted by Trained Birth Attendant's- 19\% were having 'hypothermia by maternal perception' Immediately after birth only $47 \%$ were covered fully, $52 \%$ were only partially covered, while $1 \%$ were not at all covered. Immediately post delivery only $24 \%$ were kept in skin-to-skin contact with mother. First bath immediately post birth was given in $57 \%$ infants. Conclusion: In urban slums of Indore city, in home deliveries 19\% of newborns were suffering from hypothermia even when deliveries were attended by Trained Birth Attendant. This can be attributed to faulty newborn care practices.
\end{abstract}

Keywords: Hypothermia, Neonatal care, Newborn, Urban slums

\section{Introduction}

Many practices in midwifery care are prevalent without ever having been properly assessed. Perinatal routine care in urban slums seems to be in particular need of assessment. Birth asphyxia and hypothermia are common antecedents of excessive morbidity and mortality in the neonatal period. The prevention of neonatal hypothermia in uncompromised newborns is dependent on the degree of adherence to simple routines after birth. These routines are- wiping and wrapping the baby, keeping the delivery room warm and giving opportunities for early breast feeding. The newborn responds differently to hypothermia-by 'non shivering thermogenesis' - a metabolic process whereby oxygen consumption is raised independently of muscle activity; occasionally transient shivering can be observed [1] but mostly newborn responds to cold stress by changing its position in an attempt to decrease its body surface.

Manuscript received: $16^{\text {th }}$ September 2016

Reviewed: $28^{\text {th }}$ September 2016

Author Corrected; $15^{\mathrm{h}}$ October 2016

Accepted for Publication: 27 $7^{\text {th }}$ October 2016
First bath and hypothermia: Bathing the newborn is a common routine mostly to remove the 'dirty skin'- the 'vernix caseosa'. Vernix is actually a product of fetal skin representing physiological and sterile coverage of parts of the fetal body beyond 34 to 36 wks of normal pregnancy. It has no infected material and on the contrary it has got antibacterial properties that may contribute to the protection of the newborn from bacterial infections.

\section{Methods}

This study was conducted over a period of 1 year at the Aanganwadi centres of various urban slums of Indore city at M.P. state. For these purpose 411 subjects of age 0-2 months were randomly selected.

Inclusion criteria: All term Neonates and infants up to age 2 months who are permanent residents of urban slums of Indore city 
Exclusion criteria: More than 2 months old preterm or sick newborns who needed admission in NICU within 7 days after birth or who were delivered in institutes and children of guests or relatives from other places were excluded from the study. Mothers were explained about the aims, objectives and type of study. They were asked if they understand the term 'hypothermia by maternal perception'. Only those mothers were included who had home delivery conducted by Trained Birth Attendant. Mothers who had recollection of perceiving body temperature of infants less than 2 months old, were included.

Pre-conceived and printed questionnaire was used as proforma and filled by both the investigators themselves; based on mothers interview.

Data was collected, tabulated and analysed statistically. As this is a one-time single observation study,
Confidence Interval (CI) was chosen as the best tool to gather reliable data; narrower the range, more the confidence in the data. The calculation of $95 \% \mathrm{CI}$ was done by method described by J.E.Park [2]

95\% Confidence Interval (CI): it is the range of 95\% confidence in any data To calculate CI, SEP (Standard Error of Proportion) is calculated as follows: $\mathrm{SEP}=$ $\sqrt{ }(\mathrm{pq} / \mathrm{n})$

Where,

$\mathrm{P}=$ proportion of parameter for which $95 \% \mathrm{CI}$ is to be calculated

$\mathrm{Q}=$ proportion of the rest of the parameters

$\mathrm{N}=$ sample size

$95 \% \mathrm{CI}=\mathrm{SEP} \times 1.96 \pm \mathrm{p}$

i.e. $(\mathrm{SEP} \times 1.96 \mathrm{CI})+\mathrm{p}$ to $(\mathrm{SEP} \times 1.96 \mathrm{CI})-\mathrm{p}$

For every parameter $95 \% \mathrm{CI}$ is calculated.

\section{Results}

In home delivery $19 \%$ newborns were hypothermic by maternal perception (95\% CI-0.15-0.22). Only 47\% newborns were fully covered with cloth (95\% CI-0.43-0.51) and only $24 \%$ were kept in skin contact with mother (95\%CI-0.19$0.28)$, most of the babies (57\%) were given bath immediately (95\%CI-0.52-0.61).

Table-1: Distribution according to Hypothermia by maternal perception (Home delivery)

\begin{tabular}{|c|c|c|c|}
\hline Hypothermia & No. & \% & 95\% CI \\
\hline Yes & 78 & 19 & $($ CI-0.15-0.22) \\
\hline No & 333 & 81 & $($ CI-0.77-0.84) \\
\hline Total & $\mathbf{4 1 1}$ & $\mathbf{1 0 0}$ & \\
\hline
\end{tabular}

Hypothermia was present in $19 \%$ of subjects (95\%CI-0.15-0.22)

Table-2: Distribution according to way of covering the baby

\begin{tabular}{|c|c|c|c|}
\hline Baby covered as & No. & \% & 95\% CI \\
\hline Head covered & 8 & 2 & $($ CI-0.006-0.03) \\
\hline Head +body covered & 193 & 47 & $($ CI-0.42-0.51) \\
\hline Only body covered & 206 & 50 & $($ CI-0.45-0.54) \\
\hline not covered & 4 & 1 & \\
\hline Total & $\mathbf{4 1 1}$ & $\mathbf{1 0 0}$ & \\
\hline
\end{tabular}

Only $47 \%$ were covered fully (95\%CI-0.43-0.51)

Table-3: Distribution according to status of Baby-Mother skin-to-skin contact

\begin{tabular}{|c|c|c|c|}
\hline Whether kept in skin-to-skin contact with mother & No & \% & 95\% CI \\
\hline YES & 99 & 24 & $($ CI-0.91-0.28) \\
\hline NO & 312 & 76 & $($ CI-0.71-0.80) \\
\hline TOTAL & 411 & 100 & \\
\hline
\end{tabular}

Only $24 \%$ were kept in contact with mother (95\% CI-0.19-0.28) 
Table-4: Distribution according to time since birth for first bath

\begin{tabular}{|c|c|c|c|}
\hline $\begin{array}{c}\text { First bath after how } \\
\text { many hrs since birth }\end{array}$ & No. & \% & 95\% CI \\
\hline Immediately & 234 & 57 & $($ CI-0.52-0.61) \\
\hline B/w $12-24 \mathrm{hrs}$ & 116 & 28 & $($ CI-0.23-0.32) \\
\hline B/w 24-48 hrs & 35 & 9 & $($ CI-0.06-0.11) \\
\hline B/w 48-72 hrs & 26 & $\mathbf{1 0 0}-0.03-0.08)$ \\
\hline Total & $\mathbf{4 1 1}$ & 6 & \\
\hline
\end{tabular}

Majority of the newborns (57\%) were immediately bathed (95\% CI-0.51-0.61)

\section{Discussion}

In our study overall incidence of Hypothermia was found to be $19 \%$ by maternal perception. Hands and body both were covered in only $47 \%$ newborns while $50 \%$ were kept with only body covered, $2 \%$ only head covered and $1 \%$ were not covered at all. Only $24 \%$ were kept in skin - to-skin contact with mother, 57\% were bathed immediately, $28 \%$ between $12-24 \mathrm{hrs}, 9 \%$ within 24-48 hrs and 6\% were given bath within 48$72 \mathrm{hrs}$.

A similar study in Zambia [3] found that $30.64 \%$ neonates were completely wrapped, which is similar to our study, $20.96 \%$ were incompletely wrapped; which is less than our study and $8 \%$ were not wrapped at all; which is more than our study. A similar study on uncomplicated newborn infants in Nepal [4] found that hypothermia was present in $2.9 \%$ of hospital deliveries; which is less than our study.

A similar study in Shimla [5] found that hypothermia was present in $81 \%$ of newborns on first day after birth, which is more than our study. In a community based study in Ambala city [6] incidence of hypothermia was $11.1 \%$ which is less than our study. A cross-sectional community based study of care of newborns in Nepal [7]; found that in home deliveries only $4 \%$ newborns were wrapped, which is less than our study.

In Uganda: A randomized, controlled trial [8] found that $83 \%$ neonates were hypothermic after 1 hour, which is more than our study.

A study was conducted by UHRC[9] with 15025 mothers across 45 slums in Meerut city of UP found that the incidence of hypothermia was $12 \%$, which is similar to our study, $26.5 \%$ were kept in contact with mother and $18.8 \%$ were wrapped completely; these findings are less than our study.71.5\% were wrapped partially, which is more than our study. $32 \%$ were bathed immediately, which is less than our study.

A similar study conducted in urban slums of Lucknow city, UP [10] found that $79.7 \%$ newborns were bathed immediately, which is more than our study. A study among slum dwellers in Rachna Town, Lahore [11] found that $37.2 \%$ newborns were bathed immediately, which is less than our study; $18.8 \%$ were wrapped completely, which is less than our study and only $26.5 \%$ were kept in contact with mother, which is similar to our study.

A systemic review on similar topic [12] found out that in home deliveries; range of prevalence of hypothermia was from 11 to $92.3 \%$. 92.3\% in Sarlahi, Nepal, $82 \%$ in Kathmandu, $43 \%$ in Uttar Pradesh and 25\% in Delhi, which are more than our study and $11 \%$ in Haryana, $17 \%$ in Gadchiroli; which is less than our study.

\section{Conclusion}

The incidence of Hypothermia varies in different regions and seasons. The incidence of hypothermia reported in this study should be taken as minimum as lower environmental temperatures in the night might have increased the incidence during night hours.

Since the relation between neonatal temperature and mortality is shown to be linear; appropriate practices 
like-warm delivery room, immediate drying and skin to skin contact with mother for first hours after birth and delaying first bath must be followed. While promoting the programme for prevention of neonatal hypothermia, caution should be taken to modify the guidelines according to the specific environmental situation.

\section{Funding: Nil, Conflict of interest: Nil \\ Permission from IRB: Yes}

What is already known?: Hypothermia is a common cause of excessive morbidity and mortality in neonatal period.

What this study adds?: In urban slums of Indore city incidence of hypothermia is high in home deliveries even while they are being conducted by Trained Birth Attendants. Hypothermia can fully be attributed to faulty newborn care practices.

\section{References}

1. SILVERMAN WA, FERTIG JW, BERGER AP. The influence of the thermal environment upon the survival of newly born premature infants. Pediatrics. 1958 Nov; 22 (5):876-86.

2. Park JE,Park K.A.,Textbook of preventive and social medicine Ed 13 : P :66

3. Christensson K, Ransjö-Arvidson AB, Kakoma C, Lungu F, Darkwah G, Chikamata D, Sterky G. Midwifery care routines and prevention of heat loss in the newborn: a study in Zambia. J Trop Pediatr. 1988 Oct; 34(5):208-12.

4. Anderson S, Shakya KN, Shrestha LN, Costello AM. Hypoglycaemia: a common problem among uncomplicated newborn infants in Nepal. J Trop Pediatr. 1993 Oct;39(5):273-7.
5. Kaushik SL, Grover N, Parmar VR, Kaushik R, Gupta AK. Hypothermia in newborns at Shimla. Indian Pediatr. 1998 Jul;35(7):652-6.

6. Kumar R, Aggarwal AK. Body temperatures of home delivered newborns in north India. Trop Doct. 1998 Jul; 28(3):134-6.

7. Osrin D, Tumbahangphe KM, Shrestha D, Mesko N, Shrestha BP, Manandhar MK, Standing H, Manandhar DS, Costello AM. Cross sectional, community based study of care of newborn infants in Nepal. BMJ. 2002 Nov 9;325(7372):1063.

8. Byaruhanga R, Bergstrom A, Okong P. Neonatal hypothermia in Uganda: prevalence and risk factors. J Trop Pediatr. 2005 Aug;51(4):212-5. Epub 2005 May 25.

9. UHRC,Reanalysis of NFHS-3 (2005-2006)far India and UP based on wealth index.http://www.nfhsindia.org

10. Gupta P, Srivastava V, Kumar V, Jain S, Masood J, Ahmad N, Srivastava J. Newborn Care Practices in Urban Slums of Lucknow City, UP. Indian J Community Med. 2010 Jan;35(1):82-5. doi: 10.4103/ 0970-0218.62570.

11. Aziz N.,Akhter S., Kaleem R: Newborn care practices regarding thermal protection among slum dwellers in Rachna Town, Lahore,Punjab. Special edition Annals vol 16. No.1 Jan. - Mar. 2010.

12. Lunze K, Bloom DE, Jamison DT, Hamer DH: The global burden of neonatal hypothermia - systematic review of a major challenge for newborn survival. BMC Medicine[2013, 11:24] DOI:10.1186/1741-7015-11-24.

\section{How to cite this article?}

Singh D, Singh M.P. Observation on hypothermia among infants less than 2 months in urban slums of Indore City. Int. J PediatrRes.2016;3(10):745-748.doi:10.17511/ijpr.2016.i10.05 